九州大学学術情報リポジトリ

Kyushu University Institutional Repository

\title{
Most Hypotetraploid Seedlings from Self- Pollinated Tetraploid Grapes (Vitis complexes) Have Abnormal Cotyledons
}

Park, Sung Min

Laboratoy of Horticultural Science, Faculty of Agriculture, Kyushu University

Wakana, Akira

Laboratory of Fruit Tree Science, University Farm, Faculty of Agriculture, Kyushu University

Hiramatsu, Michikazu

Laboratory of Vegetable and Ornamental Crops, University Farm, Faculty of Agriculture, Kyushu University

https://doi.org/10.5109/24309

出版情報 : 九州大学大学院農学研究院紀要. 44 (1/2)，pp.81-89，1999-11. Kyushu University バージョン：

権利関係 : 


\title{
Most Hypotetraploid Seedlings from Self-Pollinated Tetraploid Grapes (Vitis complexes) Have Abnormal Cotyledons
}

\author{
Sung Min Park', Akira Wakana ${ }^{2}$ and Michikazu Hiramatsu ${ }^{9}$ \\ ' Laboratory of Horticultural Science, Faculty of Agriculture, \\ Kyushu University, Fukuoka 812-8581, Japan \\ "Laboratory of Fruit Tree Science, University F'arm, Faculty of Agriculture, \\ Kyushu University, Kasuya-gun 811-2307, Japan \\ ${ }^{3}$ Laboratory of Vegetable and Ornamental Crops, University Farm, Faculty of Agriculture, \\ Kyushu University, Kasuya-gun 811-2307, Japan \\ (Received July 30, 1999 and accepted August 24, 1999)
}

\begin{abstract}
To establish a rapid and simple method to determine aneuploidy in seedlings derived from crosses between tetraploid grapes, chromosome number and morphology of cotyledons were examined in the seedlings from self-pollinated two tetraploid grapes, KA9301 and RB9127. Three of 24 seedlings from self-pollinated KA9301 were aneuploid plants with hypotetraploid chromosome number $75(4 x-1), 74(4 x-2)$ and $73(4 x-3)$. One of 35 seedlings from self-pollinated RB9127 was also an aneuploid plant with hypotetraploid chromosome number 74 $(4 \mathrm{x}-2)$. These four aneuploid seedlings showed almost normal growth and leaf morphology, but in three of the four aneuploid seedlings: morphology of cotyledons was highly abnormal. These results suggested the possibility that in crosses between tetraploid grapes most aneuploid seedlings were efficiently selected by their abnormal morphology of cotyledons soon after seed germination.
\end{abstract}

\section{INTRODUCTION}

Seedlessness is an important breeding character in grape (Vitis. spp.) as well as in most fruit trees. Seedless grape cultivars are classified into four types, i.e., stimulative parthenocarpy (Winkler et al., 1962), stenospermocarpy (Stout, 1936), triploid and aneuploid. Most seedless grape cultivars in the world have been bred using cultivars with the stenospermocarpic character controlled by recessive genes (Weinberger and Harmon, 1964; Constantinescu et al., 1975; Dudnik and Moliver, 1976; Loomis and Weinberger, 1979; Spiegel-Roy et al., 1990). However, application of this breeding method to the crosses between grape cultivars is restricted, since at least one of two cultivars used for the crossing must have genes controlling stenospermocarpy.

In the last decade, triploid grape cultivars such as 'King Dela, 'Osuzu' and 'Honey Seedless' were bred in Japan using crosses between various diploid and tetraploid cultivars. In vitro techniques to produce triploid grapes from $2 \mathrm{x}-4 \mathrm{x}$ crosses also were developed (Yamashita et al., 1993, 1995 and 1998). In addition to triploid breeding in grape, aneuploid breeding is also expected as another method to produce seedless grape cultivars, since only one aneuploid cultivar 'Takao' ( $2 \mathrm{n}=4 \mathrm{x}-1=75$;Yamane et al., 1978), a chance seedling from open pollinated tetraploid 'Kyoho' has become one of commercially important cultivars in Japan. GPI-2 and PGM-2 isozyme analyses indicated that 'Takao' originated either from self-pollination of 'Kyoho' or from outcross with a tetraploid cultivar very closely related to 'Kyoho' (Ohmi et al., 1993). In self-pollinations of 
tetraploid cultivars and in crosses between tetraploid cultivars, appearance of aneuploid seedlings such as 'Takao' is considered to be dependent on the failure of meiosis, since tetraploid has four homologous chromosomes in each of 19 types of chromosomes. Thus, appearance of hypertetraploid and hypotetraploid secdlings resulting from failure of meiosis I are especially expected in such cases. Except for 'Takao,' however, there is no report on the production of hypertetraploid and hypotetraploid plants from crosses between tetraploid grapes, probably because of their very low frequencies. In addition, examination of exact chromosome number in the seedlings from crosses between tetraploid grapes is very tedious and proficient work, because they have a large number of small chromosomes. Hence, simple and rapid methods to identify aneuploid seedlings are requested for the development of aneuploid grape breeding using crosses between tetraploid grapes.

In this report, we demonstrate that hypotetraploid seedlings appear among seedlings from self-pollinated tetraploid grapes and that morphology of their cotyledons is very abnormal. From these results, we suggest a simple method to select aneuploid, especially, hypotetraploid grapes.

\section{MATERIALS AND METHODS}

\section{Plant materials}

Two tetraploid grapes, KA9301 and RB9127 were used. KA9301 was an eight-year-old hybrid seedling obtained from 'Kyoho' $(4 \mathrm{x}) \times$ 'Muscat of Alexandria' $(2 \mathrm{x})$, while RB9127 was an eight-year-old hybrid seedling obtained from 'Red Pearl' $(4 \mathrm{x}) \times$ 'Muscat Bailey $A^{\prime}(2 x)$. These tetraploid grapes resulted from the fusion of diploid egg and unreduced male gamete. The two tetraploid hybrid grapes were grown under a greenhouse at Sasaguri Orchard of University Farm, Kyushu University, Fukuoka.

\section{Pollen germination test}

Pollens of KA9301 and RB9127 each were collected from just opened flowers at a full bloom stage of the clusters, and immediately cultured on pollen germination medium in $50 \times 15 \mathrm{~mm}$ sterile plastic disposable petridishes so that pollen grains were dispersed. The medium consisted of $0.8 \mathrm{~g} / \mathrm{agar}, 20 \mathrm{~g} / \mathrm{l}$ sucrose and $10 \mathrm{mg} / \mathrm{l}$ boric acid. Cultures were mainlained at $25^{\circ} \mathrm{C}$. After fourhours incubation of the cultures, the rate of pollen germination in each tetraploid grape was examined using about 600 pollen grains. In addition, diameters of all these pollen grains were measured with a micrometer under a microscope.

\section{Self-pollination}

Ten clusters of the two tetraploid grapes each were bagged several days before anthesis to prevent outcross, and the flowers were self-pollinated by tapping the bags at a full bloom stage. Fully developed seeds were excised from mature berries about four months after self-pollination. Only sinkers were sown in $300 \times 400 \mathrm{~mm}$ seedling culture boxes filled with moist sand in September 1998 and stored under natural conditions. They were carried in a greenhouse in February of the next year to facilitate seed germination. 


\section{Chromosome observation}

The root tips of seedlings from self-pollinations were collected just after the expansion of cotyledons, pre-treated with $2 \mathrm{mM} 8$-hydroxyquinoline at room temperature for first 2 hours and then at $4{ }^{\circ} \mathrm{C}$ for 2 hours, and fixed in acetic alcohol $(1: 3 \mathrm{v} / \mathrm{v})$ at $4{ }^{\circ} \mathrm{C}$ for 2 hours. They were washed with distilled water and macerated in a solution of enzyme mixture for 30 to 60 minutes at $38^{\circ} \mathrm{C}$. The solution consisted of $4 \%$ Cellulase RS (Yakult), $1 \%$ Pectolyase Y23 (Seishin Pharmaceutical), $0.07 \mathrm{M} \mathrm{KCl}$ and $0.075 \mathrm{M} \mathrm{Na}_{2}$ EDTA. It was adjusted at pH 4.0 with $0.1 \mathrm{M} \mathrm{HCl}$ (Zhuang et al., 1990). After washing with distilled water three times, the macerated root tip was placed on a glass slide with a few drops of acetic alcohol $(1: 3 \mathrm{v} / \mathrm{v})$ solution, spread by tapping with fine tweezers and air dried under room temperature conditions. The air dried specimens were stained with $4 \%$ Giemsa diluted with $1 / 15 \mathrm{M}$ phosphate buffer $(\mathrm{pH} \mathrm{6.8)}$ for 5 to 10 minutes and air dried again. They were mounted in Permount and observed under a microscope of 1000 magnifications. Chromosome number was exactly counted in at least three cells per seedling.

\section{Observation of seedling morphology}

Morphology of cotyledons was observed just after the expansion of them, and then the seedlings were transplanted in $240 \times 300 \mathrm{~mm}$ polyethylene pots filled with soil and leaf mold mixture (2:1). Morphology of leaves and stems of these seedlings was observed about four months after transplanting.

\section{RESULTS}

A total of 59 seeds germinated and grew to seedlings being available for this study. Chromosome numbers of all the seedlings were determined (Table 1). In self-pollination of KA9301, 24 of 54 seeds germinated. Out of the 24 seedlings, thrce were aneuploid plants with hypotetraploid chromosome number $75(4 x-1), 74(4 x-2)$ and $73(4 x-3)$, while 21 were identified to be tetraploid plants with 76 chromosomes. In self-pollination of RB9127, 35 of 64 seeds germinated. One of the 35 seedlings was an aneuploid plant with $74(4 x-2)$ chromosomes (Fig. 1), while 34 seedlings were tetraploids.

In four of the 24 seedlings from self-pollinated KA9301, abnormal morphology of cotyledons was observed (Fig. 2). Out of the four seedlings with abnormal cotyledons, three were aneuploids and one was tetraploid. In one of the cotyledons of the tetraploid

Table 1. Aneuploidy and morphology of cotyledons in seedlings from two self-pollinated tetraploid grapes.

\begin{tabular}{cccccc}
\hline $\begin{array}{c}\text { Chomosome } \\
\text { number of } \\
\text { seedling } \\
\text { (Ploidy) }\end{array}$ & $\begin{array}{c}\text { No. of seedlings from } \\
\text { KA9301 in indicated } \\
\text { morphology of cotyledons }\end{array}$ & & $\begin{array}{c}\text { No. of seedlings from } \\
\text { RB9127 in indicated } \\
\text { morphology of cotyledons }\end{array}$ \\
\cline { 2 - 3 } \cline { 5 - 6 } $76(4 \mathrm{x})$ & 20 & 1 & & 33 & Normal \\
$75(4 \mathrm{x}-1)$ & 0 & 1 & & 0 & 0 \\
$74(4 \mathrm{x}-2)$ & 0 & 1 & & 1 & 0 \\
$73(4 \mathrm{x}-3)$ & 0 & 1 & & 0 & 0 \\
Total & 20 & 4 & 34 & 1 \\
\hline
\end{tabular}




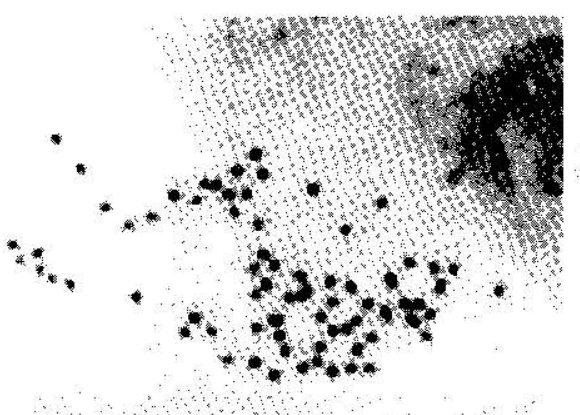

$\mathbf{A}$
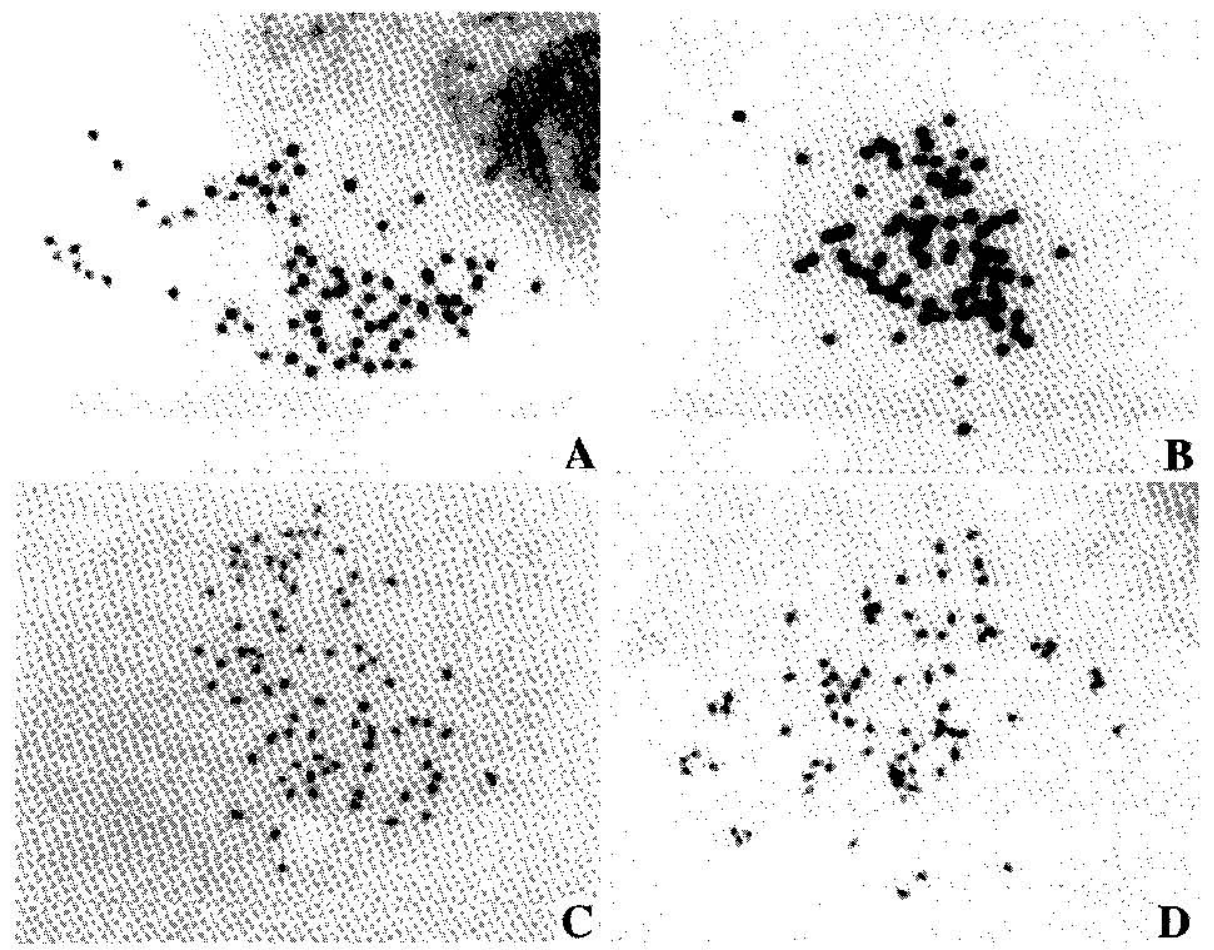

Fig. 1. Metaphase figures in root tip cells of ancuploid scedlings from self-pollinated tetraploid grapes.

A: Seedling of KA9301, $2 n=4 x-2=74, \times 3000 ; 8$ : Seedling of RB9127, $2 n=4 x-2=74, \times$ 3000; C: Seedling of KA9301, $2 n=4 x-3=73, \times 2400 ; D$ : Seedling of KA9301, $2 n=4 x-1=75$, $\times 2400$.

seedling, a deep and narrow incision was observed from the terminal end to central part. Only one of 35 seedlings from RB9127 showed abnormal morphology in its cotyledons. 'The cotyledons had entire margin, but proliferation of very small and narrow leaf like structure was observed on the midrib of adaxial side. However, it was not an aneuploid but tetraploid. On the other hand, one of the 34 seedlings with normal cotyledons was aneuploid $(4 \mathrm{x}-2)$. The cotyledons of this $4 \mathrm{x}-2$ seedling were classified as normal but showed slighty undulate margin (Fig. 2).

The four hypotetraploid seedlings continued to grow almost normally as compared with tetraploid seedlings from the same self-pollinations. When growth was compared between the four hypotetraploid seedlings, $4 x^{-1}$ seedling and $4 x^{-}-2$ seedling from KA9301 were very vigorous, whereas $4 \mathrm{x}-2$ seedling from RB9127 and $4 \mathrm{x}-3$ seedling from KA9301 were slow in growth. In addition, 4x-3 seedling from KA9301 had short internode and relatively small leaves, and the first four leaves of the seedling showed slightly abnormal morphplogy (Fig. 3).

Percentages of pollen grains germinating on the artificial medium were relatively low in the two tetraploid grapes KA9301 and RB9127. In KA9301, 128 of 615 pollen grains germinated, while in RB9127 138 of 671 pollen grains germinated. Diameter of almost all 


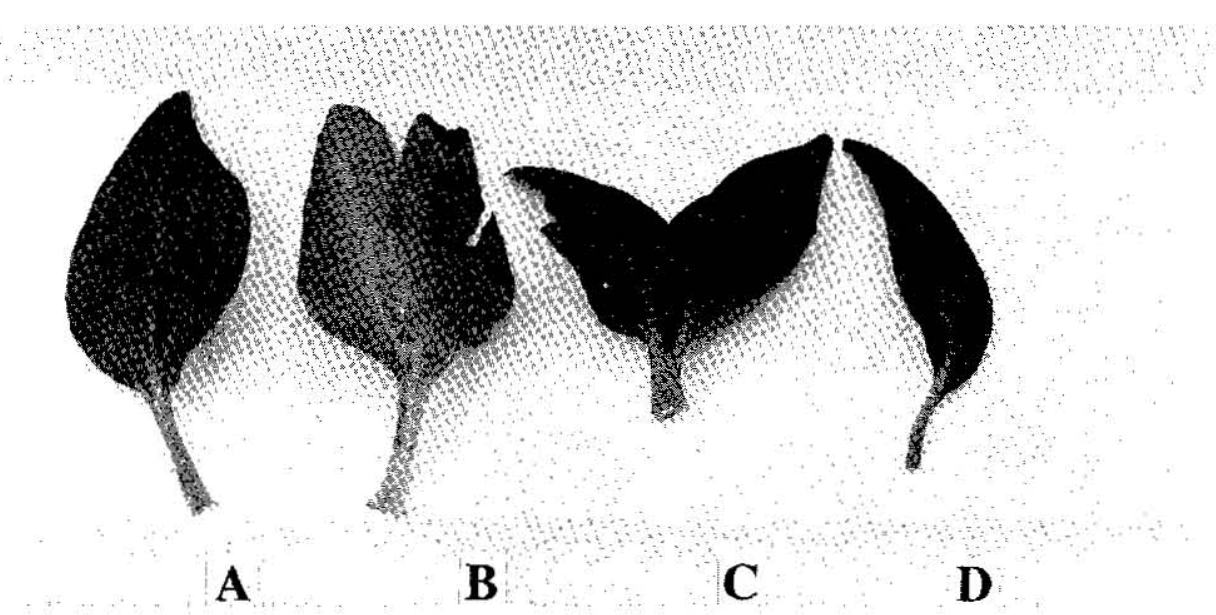

Fig. 2. Morphology of cotyledons of aneuploid seedlings from self-pollinated tetraploid grapes.

A: Adaxial surface of almost normal cotyledon of a seedling $(2 n=4 x-2=74)$ from $R B 9127$. The cdige of cotyledon is smooth and no lobing is observed. Notc also the symmetric veins.

B: Adaxial surface of abnormal cotyledon of a seeding $(2 n=4 x-2=74)$ from KA9301. Note the irregular shape, presence of lobing, asymmetric arrange of veins and lack of a midrib.

C: Abaxial surface of abnormal colyledon of a seedling $(2 n=4 x-3=73)$ from KA9301. The cotyledons are imperfectly fused at the basal hall. Note also the presence of lobing.

D: Abaxial surface of abnormal cotyledon of a scedling $(2 n=4 x-1=75)$ from KA9301. The cotyledon is small in size, narrow in shape and asyrtunetric in shape.

pollen grains germinating ranged from $271033 \mu \mathrm{m}$ in the two tetraploids and was $31 \mu \mathrm{m}$ in average (Fig. 4). In RB9127, however, a few of relatively large pollen grains (35 $37 \mu \mathrm{m}$ in daimeter) also germinated. Histogram showing frequency distribution of pollen size was symmetric in RB9127, whereas it was asymmetric in KA9301, in which most of pollen grains with diameters between $21 \mu \mathrm{m}$ and $26 \mu \mathrm{m}$ formed a large peak in the histogram of KA9301 pollen. The difference of frequency distribution of pollen size between RB9127 and KA9301 was mainly due to the presence of this large peak and lacking of a large number of pollen grains with diameter more than the average diameter $31 \mu \mathrm{m}$ in KA9301. Diameters of all pollen grains ranged from 13 to $40 \mu \mathrm{m}$ in KA9301 while in $\mathrm{RB} 9127$ they ranged from 13 to $49 \mu \mathrm{m}$.

\section{DISCUSSION}

In autotetraploids, reduced fertility results not only from meiotic irregularities but from gene dose imbalance (Sybenga, 1992). The very low rates of pollen germination and seed set in self-pollinated tetraploids, KA9301 and RB9127, are considered to result from both effects. However, appearance of hypotetraploid seedlings is obviously dependent on the meiotic irregularities in the two tetraploid grapes. According Rieger et al. (1976), aneuploidy can be caused by any of the four following disturbances: (1) loss of chromosomes in miotic or meiotic cells, often caused by lagging chromosomes, (2) non-disjunction of chromosomes or chromatids, or failure of such genetic units to 


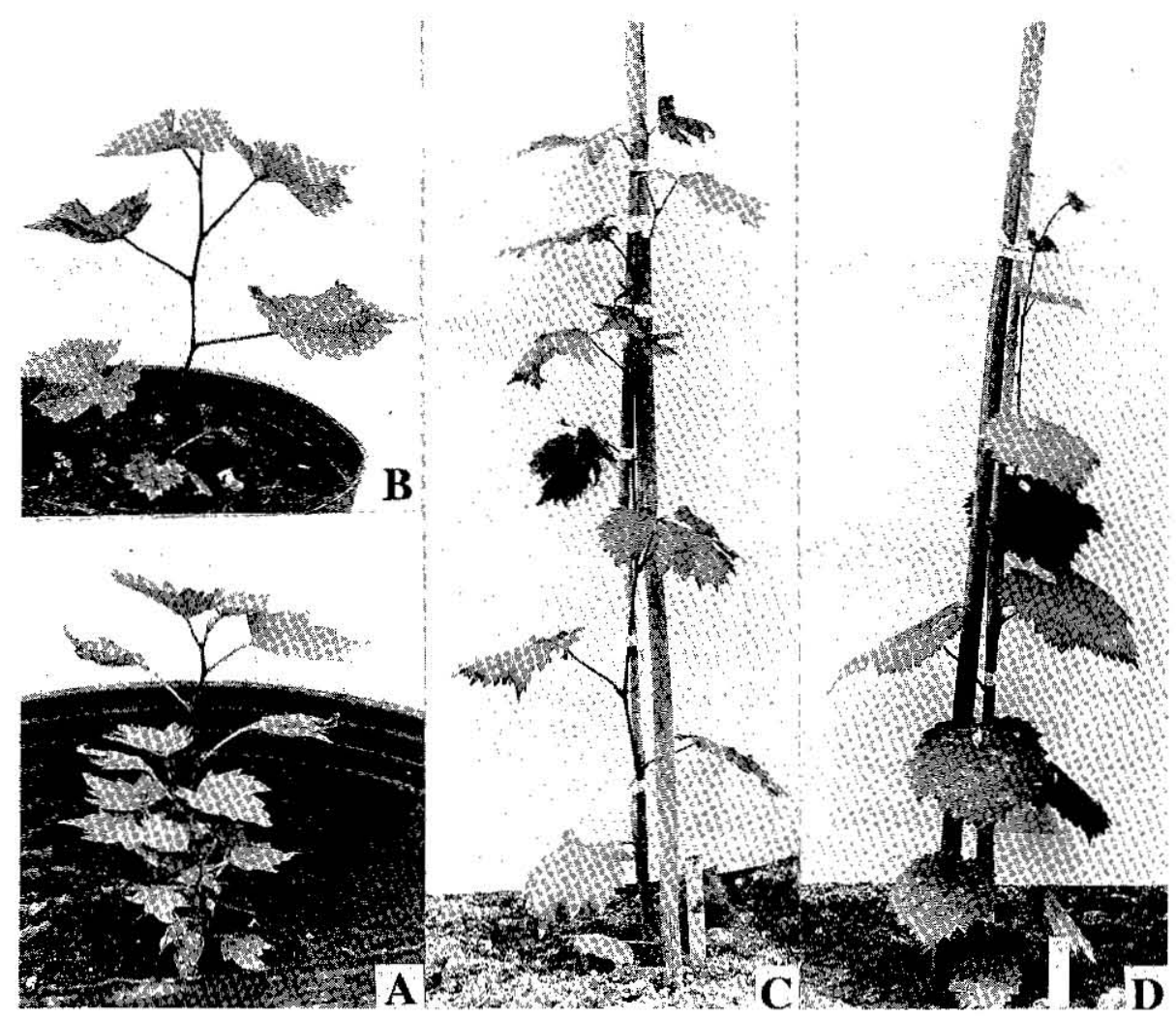

Fig. 3. Aneuploid seedlings derived from self-pollinated KA9301 and RB9127 about three months after germination.

A: Seedling of KA9301, $2 n=4 x-3=73 ; B$ : Seedling of RB9127, $2 n=4 x-2=74$

C: Seedling of KA9301, $2 n=4 x-2=74$; D: Seedling of KA9301, $2 n=4 x-1=75$

separate properly, (3) irregularities of chromosome distribution during meiosis of odd polyploids, and (4) the occurence of multipolar mitosis.

It is considered that in the case of KA9301, loss of chromosomes during meiosis may be caused by laggards, since no hypertetraploids appeared and since a loss of either one, two or three chromosomes occurred in the three hypotetraploid seedlings. The asymmetric frequency distribution of pollen size in KA9301 (Fig. 4) may partially support this conclusion. In the pollen mother cells of a tetraploid grape cultivar 'Red Pearl,' we found one to four univalents in relatively high frequencies, i.e., $28 \%$ for one, $8 \%$ for two, $4.5 \%$ for three and $2 \%$ for four univalents (unpublished data). Univalents like this lag at the equator and get lost in most cases. However, further study on meiotic events in KA9301 will be necessary to ascertain this hypothesis.

It is known that in autotetraploids the quadrivalent also will not always segregate 2:2 (Sybenga, 1992; Singh, 1993). The failure of the quadrivalent to separate properly can cause hypo- and hypertetraploid chromosome numbers. The symmetric frequency 


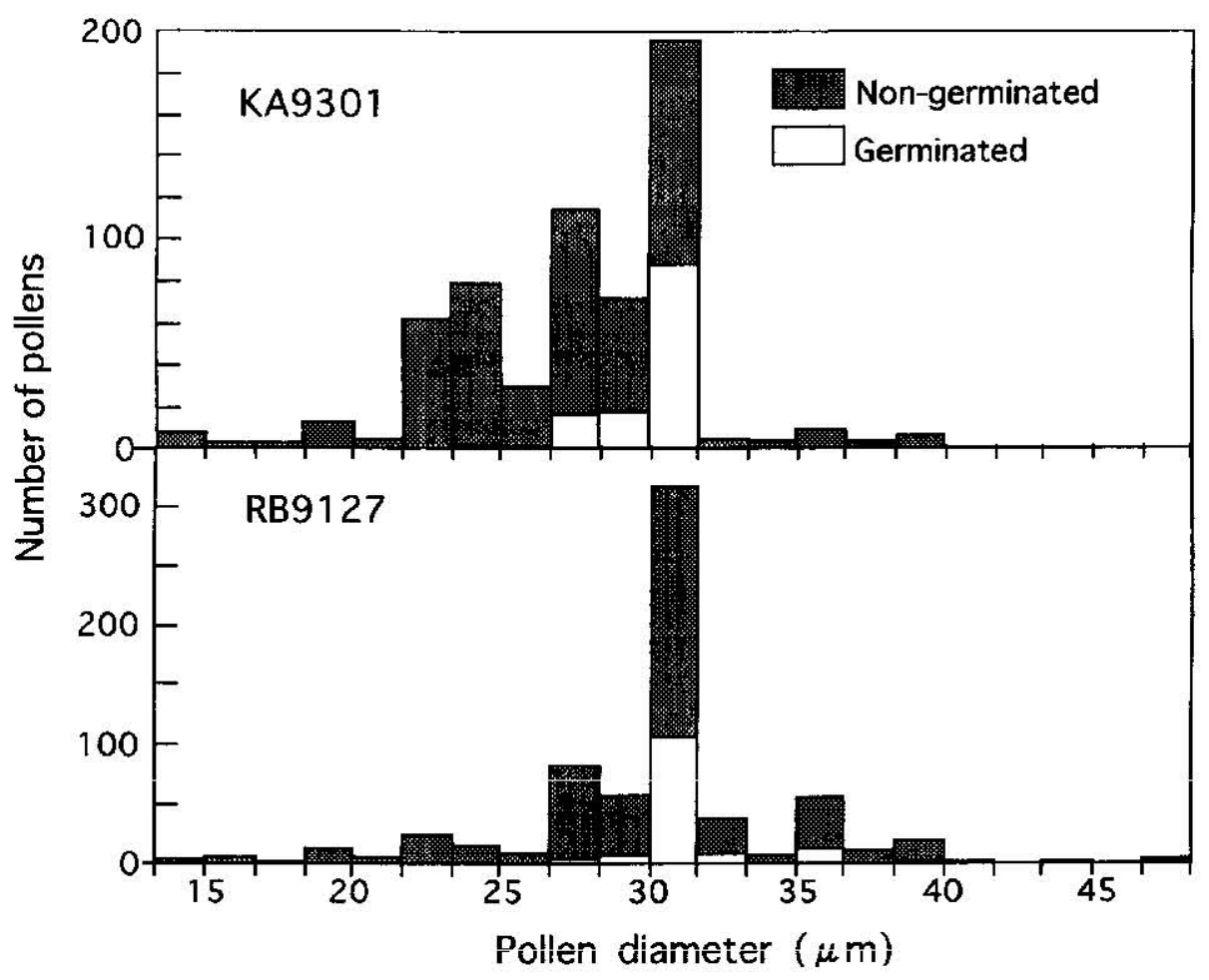

Fig. 4. Frequency distribution of pollen size in two tetraploid grapes, KA9301 and RB9127. The pollen size was measured four hours after culture on $0.8 \mathrm{~g} / \mathrm{l}$ agar medium supplemented with $20 \mathrm{~g} / 1$ sucrose and $10 \mathrm{mg} / \mathrm{l}$ boric acid.

distribution of pollen size in RB9127 (Fig. 4) may partially support this, but further study will be required to ascertain whether the hypotetraploid in RB9127 resulted from the disjunction of chromosomes or not.

Diameter of $1 x$ pollen from diploid grapes is about $25 \mu \mathrm{m}$ and that of $2 \mathrm{x}$ polien from tetraploid grapes is about $31 \mu \mathrm{m}$ (Dermen, 1954; Martens et al., 1989; Zhang et al., 1998). Among the pollen grains germinating, a small number of giant pollens with a diameter of 35 $37 \mu \mathrm{m}$ were observed in RB9127 together with about $31 \mu \mathrm{m}$ pollens. These giant pollens are considered to be unreduced $4 \mathrm{x}$ or near $4 \mathrm{x}$ pollens resulting from the failure of meiosis in the tetraploid grape. The hexaploid embryos resulting from the fertilization of a $2 \mathrm{x}$ egg and the $4 \mathrm{x}$ pollen are considered to degenerate during embryogenesis as reported in various interploid crosses (Sanford, 1983).

The most interesting result of this study is a relationship between hypotetraploidy and abnormal cotyledon morphology. The abnormal cotyledon morphology attributes to the disturbance of morphogenesis during embryogenesis. In tetraploid embryos with balanced genome, expression of genes controlling morphogenesis is normal, but in hypotetraploid embryos lacking one or more chromosomes it is considered to be abnormal. In addition, it may be considered that in hypotetraploid seeds the function of 
endosperm during their development is also different from that in tetraploid seeds. However, occurrence of abnormal cotyledons in two tetraploid seedlings suggests that in tetraploid seeds disturbance of normal morphogenesis of cotyledons also occures during their development depending on some factors intrinsic to the embryos, the environment and so on. On the other hand, the degree of abnormal morphology in cotyledons of hypotetraploids may be highly dependent on the types and number of chromosomes lacking.

For practical applications of abnormal cotyledon morphology to hypotetraploid grape breeding, the characteristics of hypotetraploids are of considerable importance. All hypotetraploid seedlings obtained in this study showed normal growth and development as tetraploid seedlings from the same pollinations showed. A hypotetraploid cultivar 'Takao' has been cultivated as one of the major cultivars in Japan. These facts indicates that hypotetraploid grapes have potential to develop as economically important cultivars with various desirable characters such as seedlessness.

In general, meiotic irregularities cause aneuploidy in the progeny, which may have quite undesirable consequences. However, the sensitivity for aneuploidy is the greatest at low ploidy levels and decreases when the number of genomes increases (Sybenga, 1992). It is inferred from this result and the reports of triploid, tetraploid and hexaploid grapes with vegetative vigour (Olmo, 1952; Sanford, 1983) that ancuploidy in grape has a very pronounced effect around the triploid and tetraploid level.

The present study clearly indicated that vigorous hypotetraploid seedlings can obtain from self-pollinations of tetraploid grapes, and that most of the hypotetraploid seedlings have cotyledons showing abnormal morphology. Application of the cotyledon morphology as a marker for the detection of hypotetraploids will greatly improve the efficiency of hypotetraploid seedless grape breeding.

\section{ACKNOWLEDGEMENTS}

We wish to thank Prof. E. Matsuo, Laboratory of Horticultural Science, for reading this manuscript.

\section{REFERENCES}

Constantinescu, G., A. Pena and A. Indreas 1975 Inheritance of some qualitative and quantitative characters in the progeny of crosses between functionally female (gynodynamic) and apyrene (androdynamic) varictics. Probleme de Genetica Teoretica, Si Aplicata, 7: 213-241 (In Romanian with English summary)

Dermen, H. 1954 Colchiploidy in grapes. J. Heredity 45: 159-172

Dudnik, N. A. and M. G. Moliver 1976 Inheritance of seedlessness in grape in the south of the Ukrainian SSR. Referativnyi Zh., 5.55.118: 105-113 (In Russian with English summary)

Loomis, N. H. and J. H. Weinberger 1979 Inheritance studies of seedlessness in grapes. J. Amer. Soc. Hort. Sci., 104: 181-184

Martens, M. H. R., B. I. Reisch and M. C. Mauro 1989 Pollen size variability within genotypes of Vitis. HortScience, 24(4): $659-662$

Ohmi, C., A. Wakana and S. Shiraishi 1993 Study of the parentage of grape cultivars by genetic interpretation of GPI-2 and PGM-2 isozymes. Euphytica, 65: 195-202

Olmo, H. P. 1952 Breeding tetraploid grape. Proc. Amer. Soc. Hort. Sci, 59: 285-290

Rieger, R., A. Michaelis and M. M. Green 1976 Glossary of genetics and cytogenetics. Classical and 
molecular. Springer-Verlag, Berlin

Sanford, J. C. 1983 Ploidy manipulations. In "Methods in fruit breeding", Vol. 4, J. N. Moore and J. Janick Purdue Lniv. Press, West Lafayette, pp. 100-123.

Singh, R. J. 1993 Plant cytogenetics. CRC Press, London

Spiegel-Roy, P., I. Baron and N. Sahar 1990 Inheritance of seedlessness in seeded $\times$ seedless progeny of Vitis vinifera L. Vitis, 29: 79-83

Stout, A. B. 1936 Seedlessness in grapes. New York State Agric. Exp. Sta. (Geneva) Tech. Bull. pp. 238

Sybenga, I. 1992 Cytogenetics in plant breeding. In "Monographs on theoretical and applied genetics", Vol. 17. Springer-Verlag. Berlin

Weinberger, J. H. and F. N. Harmon 1964 Seedlessness in vinifera grapes. Proc. Amer. Soc. Hort. Sci., 85: $270-274$

Winkler, A. J., J. A. Cook., W. M. Kliewer and L. A. Lider 1962 General viticulture. California Univ. Press, Berleley

Yamane, H, A. Kurihara and R. Tanaka 1978 Studies on polyploidy breeding in grapes. I. Chromosome numbers of large-berried grape varieties grown in Japan. Bull. Fruit Tree Res. Stn., E2: 1-8 (In Japanese with English summary)

Yamashita, H., I. Shigehara and T. Haniuda 1998 Production of triploid grapes by in ovulo embryo culture. Vitis, $\mathbf{3 7}$ (3): 113-117

Yamashita, H., T. Handiuda and H. Siba 1995 In vitro culture of embryos obtained by crossing tetraploid cultivar Kyoho with diploid cultivars. J. Japan. Soc. Hort. Sci., 63: 719-724

Yamashita, H., S. Horiuchi and T. Taira 1993 Development of seeds and the growth of triploid seedlings obtained from reciprocal crosses between diploids and tetraploids grapes. J. Japan. Soc. Hort. Sci., 63: $249-255$

Zhang, X. Z., G. J. Liu and D. M. Zhang 1998 Occurrence and cytogenetic development of unreduced pollen in Vitis. Vitis, $\mathbf{3 7}(2): 63-65$

Zhuang D. H., A. Kitajima, M. Ishida and Y. Sobajima 1990 Chromosome numbers of Diospyros kaki cultivars. J. Japan. Soc. Hort. Sci., 69(2): 289-297 (In Japanese with English summary) 